\title{
Specificity of immunoblotting analyses in eosinophilic meningitis
}

\author{
Kanlayanee Sawanyawisuth ${ }^{1}$, Kittisak Sawanyawisuth ${ }^{2,5} /{ }^{+}$, Pewpan M Intapan ${ }^{3,5}$, Piyarat Khotsri ${ }^{3}$, \\ Jaturat Kanpittaya ${ }^{4,5}$, Verajit Chotmongkol ${ }^{2,5}$, Wanchai Maleewong ${ }^{3,5}$ \\ ${ }^{1}$ Department of Biochemistry ${ }^{2}$ Department of Medicine ${ }^{3}$ Department of Parasitology \\ ${ }^{4}$ Department of Radiology, Faculty of Medicine ${ }^{5}$ The Research and Diagnostic Centre for Emerging Infectious Diseases, \\ Khon Kaen University, 123 Mitraparp Friendship Rd, 40002 Khon Kaen, Thailand
}

Angiostrongylus cantonensis and Gnathostoma spinigerum are the two most common causative parasites of eosinophilic meningitis (EOM). Serological tests are helpful tools for confirming the identity of the pathogen. Recent reports determined the specificity of such tests by using normal healthy controls. There have been limited studies done to rule out the cross-reactivity between these two causative parasites of EOM. This study aims to assess the specificity of the serological test in EOM by using each condition as a control for the other. Thirty-three patients with a diagnosis of EOM were enrolled. Sera from 22 patients with a positive 29-kDa antigenic diagnostic band of A. cantonensis were tested for the 21 and 24-kDa antigenic bands of G. spinigerum. Similarly, sera of 11 gnathostomiasis patients were tested for the 29-kDa diagnostic band for A. cantonensis. Only one patient in the angiostrongyliasis group had a positive result for the 21 and $24-k D a$ antigenic bands of $\mathrm{G}$. spinigerum, while no gnathostomiasis patients showed a positive result for the 29-kDa antigenic band of A. cantonensis. The specificity of the 21 and 24-kDa antigenic bands for gnathostomiasis and the 29-kDa antigenic band for A. cantonensis was $95.5 \%$ and $100 \%$, respectively. The antigenic bands for the diagnosis of gnathostomiasis and angiostrongyliasis in EOM were highly specific.

Key words: specificity - eosinophilic meningitis - immunoblotting - Angiostrongylus cantonensis - Gnathostoma spinigerum

Eosinophilic meningitis $(\mathrm{EOM})$ is a condition clinically diagnosed by evidence of more than $10 \%$ of the total white blood cell count being eosinophils in cerebrospinal fluid (CSF) (Kuberski 2006, Wilson \& Weller 2006, Sawanyawisuth \& Sawanyawisuth 2008). It is an emerging condition and most commonly found in Southeast Asia, particularly in the Northeastern part of Thailand. Recently, it has been reported worldwide (Wang et al. 2008).

Angiostrongylus cantonensis and Gnathostoma spinigerum are the two main causative organisms of EOM (Punyagupta et al. 1990, Solomon et al. 2006). Even though both angiostrongyliasis and gnathostomiasis can be differentiated by clinical manifestations, the identity of the causative agent might be unclear or obscure in the diagnosis in some patients (Ramirez-Avila et al. 2009) and could lead to improper clinical diagnosis and treatment.

Several serological tests have been shown to be diagnostic tests for angiostrongyliasis and gnathostomiasis. Most studies of human EOM had normal healthy subjects or various helminthically infected subjects as controls (Nopparatana et al. 1991, Tapchaisri et al. 1991, Eamsobhana et al. 2001, Maleewong et al. 2001, Anantaphruti et al. 2005, Laummaunwai et al. 2007, Intapan et al. 2010). There are limited studies ruling out cross-reactivity between the two causative parasites of EOM.

\footnotetext{
Financial support: the Higher Education Research Promotion and National Research University Project of Thailand, Office of the Higher Education Commission

+Corresponding author:kittisak@kku.ac.th

Received 8 January 2011

Accepted 10 June 2011
}

Immunoblotting is a diagnostic method for both human angiostrongyliasis and gnathostomiasis. The detection of circulating antibodies against specific antigenic bands is the principle of the test. The widely used antigenic bands for angiostrongyliasis and gnathostomiasis are 29 and 21 or 24-kDa, respectively (Maleewong et al. 2001, Intapan et al. 2010). This study aims to show the specificity of diagnostic bands by immunoblotting for angiostrongyliasis and gnathostomiasis in eosinophilic meningitis. Patients with EOM caused by $A$. cantonensis will serve as controls for the diagnostic test of G. spinigerum and vice versa.

\section{PATIENTS, MATERIALS AND METHODS}

The inclusion criteria for the study were patients diagnosed with EOM who had results of serological tests for both $A$. cantonensis and G. spinigerum. EOM was diagnosed if more than $10 \%$ of CSF eosinophils of the total CSF white blood cell count and if CSF staining for organisms, cryptococcal antigen testing and cultures was negative (Sawanyawisuth \& Sawanyawisuth 2008).

Cases were defined as angiostrongyliasis if (i) there was a history of eating raw freshwater snails, freshwater prawns, crabs, frogs, monitor lizards or contaminated vegetables within the past three months and (ii) there were positive serum antibodies to the $29-\mathrm{kDa}$ antigenic polypeptide of $A$. cantonensis (Maleewong et al. 2001).

A diagnosis of gnathostomiasis was made if the patients had a history of exposure to G. spinigerum larvae and had positive serum antibodies to the $21-\mathrm{kDa}$ or $24-$ $\mathrm{kDa}$ antigenic polypeptide of $G$. spinigerum (Intapan et al. 2010). A history of eating or contact with raw freshwater fish, poultry, snakes or frogs was considered a risk factor for gnathostomiasis. In addition, a history of mi- 
gratory swelling, radicular pain or suggestive radiologic brain imaging such as track-like intracerebral haemorrhaging was supporting evidence for gnathostomiasis.

Sera of all patients were tested for specific antibodies against the 21 and/or 24-kDa antigenic bands of $G$. spinigerum and the $29-\mathrm{kDa}$ band of $A$. cantonensis by immunoblotting. The methods of the technique are described below and are composed of two steps: (i) the creation of antigenic bands by sodium dodecyl sulphatepolyacrylamide gel electrophoresis (SDS-PAGE) and (ii) the detection of antibodies against the specific polypeptide band by immunoblot analysis.

SDS-PAGE - Crude somatic antigen of young adult female (YAF) A. cantonensis or advanced third stage (aL3) G. spinigerum used in the SDS-PAGE technique (Laemmli 1970) was prepared according to the method as described by Maleewong et al. (2001). Briefly, YAF $A$. cantonensis from rats or aL3 G. spinigerum from mice were homogenised in distilled water containing a mixture of proteinase inhibitors followed by ultrasonic disintegration. The supernatant of the antigen was collected after centrifugation and then the protein was concentrated and lyophilised. The crude somatic antigen of $A$. cantonensis or G. spinigerum was then separated by molecular mass in $10-18 \%$ gradient separating or $12 \%$ SDS-PAGE gels, respectively. The molecular weight of the polypeptide bands of antigen were estimated by comparing their mobility to the standard molecular weight markers.

Immunoblot analysis - This technique is composed of two steps: electrophoresis transfer blot and enzyme immunoassay (EIA). The components of the polypeptide bands of each antigen on SDS-PAGE gels were blot electrotransferred onto nitrocellulose membranes according to the method of Towbin et al. (1979), with some modification. The transfer blot sheet was cut into $0.4 \times 5.5 \mathrm{~cm}$ strips for detection of specific antibodies in each serum sample. The EIA process on nitrocellulose membranes was determined by the method previously described (Maleewong et al. 2001, Laummaunwai et al. 2007). Briefly, non-specific binding sites on the antigen strip were blocked by soaking in a solution of $1 \%$ skim milk in phosphate buffer solution with Tween 20 (blocking buffer) for $30 \mathrm{~min}$. After washing with blocking buffer, each strip was incubated with the optimal diluted solution of each serum sample for $2 \mathrm{~h}$. The strips were washed with blocking buffer, probed with an optimal diluted solution of goat anti-human IgG labelled horseradish peroxidase conjugate (Zymed Laboratories Inc) for $2 \mathrm{~h}$ and then washed again with the blocking buffer. The colour of the reactive polypeptide bands was developed after reacting with 3,3'-diaminobenzidine tetrahydrochloride substrate solution for $5 \mathrm{~min}$. The reaction was stopped by washing in DW and air drying. Positive pooled sera of angiostrongyliasis or gnathostomiasis were used as positive controls. Negative pooled sera of healthy persons were used as negative controls. The negative controls were persons who had no clinical diagnosis of EOM and who had negative results against the 21, 24 and 29-kDa antigenic bands.
To determine the specific antibody to the $29-\mathrm{kDa}$ polypeptide antigen of $A$. cantonensis, a serum dilution at 1:100 and a conjugate dilution at 1:5,000 revealed the best resolution, while the specific antibody against the 21 and/or 24-kDa polypeptide antigen of G. spinigerum gave a high resolution band with a serum dilution of 1:200 and a conjugate dilution of 1:15,000.

Data analysis - The cross reaction of the 29-kDa antigenic polypeptide of $A$. cantonensis against the sera of gnathostomiasis patients was determined and vice versa. The specificity of each diagnostic band was calculated.

Ethics - The study protocol was reviewed and approved by the institutional review board and the Ethical Committee of Khon Kaen University.

\section{RESULTS}

Thirty-three patients with a diagnosis of EOM were enrolled. Of those, 22 had positive results for the $29-\mathrm{kDa}$ antigenic diagnostic band of $A$. cantonensis, whereas 11 had positive results for the 21 or $24-\mathrm{kDa}$ antigenic band of G. spinigerum. Sera of 22 angiostrongyliasis patients were tested for the 21 and 24-kDa diagnostic bands of G. spinigerum. Similarly, sera of 11 gnathostomiasis patients were tested for the 29-kDa diagnostic band of $A$. cantonensis.

Only one patient in the angiostrongyliasis group had a positive result for the 21 or $24-\mathrm{kDa}$ antigenic bands of G. spinigerum (Table I), while no gnathostomiasis patients showed a positive result for the $29-\mathrm{kDa}$ antigenic band of A. cantonensis (Table II). The specificity of the 21 , or 24 and $29-\mathrm{kDa}$ antigenic bands for gnathostomiasis and angiostrongyliasis in EOM was $95.5 \%$ and $100 \%$, respectively.

\section{TABLE I}

A 2 × 2 table of immunoblotting analysis of the 21 or $24-\mathrm{kDa}$ antigenic band for Gnathostoma spinigerum in eosinophilic meningitis by using eosinophilic meningitis patients caused by Angiostrongylus cantonensis as controls

\begin{tabular}{lcc}
\hline & $\begin{array}{c}\text { Gnathostomiasis } \\
(\mathrm{n}=11)\end{array}$ & $\begin{array}{c}\text { Angiostrongyliasis } \\
(\mathrm{n}=22)\end{array}$ \\
\hline Positive 21 or $24-\mathrm{kDa}$ & 11 & 1 \\
Negative 21 or $24-\mathrm{kDa}$ & 0 & 21
\end{tabular}

TABLE II

A 2 × 2 table of immunoblotting analysis of the $29-\mathrm{kDa}$ antigenic band for Angiostrongylus cantonensis in eosinophilic meningitis by using eosinophilic meningitis patients caused by Gnathostoma spinigerum as controls

\begin{tabular}{lcc}
\hline & $\begin{array}{c}\text { Angiostrongyliasis } \\
(\mathrm{n}=22)\end{array}$ & $\begin{array}{c}\text { Gnathostomiasis } \\
(\mathrm{n}=11)\end{array}$ \\
\hline Positive $29-\mathrm{kDa}$ & 22 & 0 \\
Negative $29-\mathrm{kDa}$ & 0 & 11 \\
\hline
\end{tabular}




\section{DISCUSSION}

EOM in Southeast Asia and worldwide is mainly caused by either A. cantonensis or G. spinigerum (Solomon et al. 2006). Most serological diagnostic studies for these two parasites had very high specificity, but used normal subjects as controls (Nopparatana et al. 1991, Tapchaisri et al. 1991, Eamsobhana et al. 2001, Maleewong et al. 2001, Anantaphruti et al. 2005, Laummaunwai et al. 2007, Intapan et al. 2010). We herein confirm that the 21 or 24-kDa antigenic diagnostic band for gnathostomiasis and the 29-kDa antigenic diagnostic band for angiostrongyliasis in EOM are highly specific.

Recently, both 21 and 24-kDa antigenic bands have been shown to be specific for neurognathostomiasis (Intapan et al. 2010). Only one patient with a positive $29-\mathrm{kDa}$ antigenic band for $A$. cantonensis had a positive result for the 21 or $24-\mathrm{kDa}$ antigenic band of G. spinigerum. Three possible explanations are as follows: (i) the patient had been infected by G. spinigerum or A. cantonensis in the past because $\operatorname{IgG}$ was used in immunoblot analysis, (ii) there might be cross reaction between $A$. cantonensis and G. spinigerum or (iii) the patient had a coinfection from eating raw freshwater shrimp which contained both $A$. cantonensis and $G$. spinigerum larvae.

There are other possible causes of eosinophilic meningitis, such as Toxocara canis or Baylisascaris procyonis (Solomon et al. 2006). However, both of these conditions are very rare. By clinical features, history of larvae exposure and geographic location, these two parasites can be differentiated from $A$. cantonensis and G. spinigerum. In addition, both parasites are rare causes of eosinophilic meningitis; they usually cause eosinophilic meningoencephalitis, which is more severe and presents with dramatically altered mental status. Most patients with EOM have a normal mental status (Solomon et al. 2006).

Eosinophilic meningoencephalitis caused by $T$. canis has been reported in two children who had history of contact with puppy faeces (Moreira-Silva et al. 2004), while $B$. procyonis was also reported in children who had contact with raccoon faecal matter (Chun et al. 2009, Page et al. 2009). In a literature review, there are a very limited number of cases in which these two parasites caused only eosinophilic meningitis. Very rarely, Paragonimus westernmani may be a cause of eosinophilic meningitis. However, the central nervous system complication of $P$. westernmani is usually accompanied by cavitary lung lesions and brain calcification or a "soap bubble" appearance (Solomon et al. 2006).

Even though the specificity of the 29-kDa antigenic band for angiostrongyliasis is very high, the sensitivity is only $55.6 \%$. A negative result of the test is not excluded in the diagnosis of angiostrongyliasis in clinically suspected patients. Another limitation of this study was the small number of subjects tested for all antigenic bands. The specificity of the tests might be lower if more subjects were enrolled. Further cohort study may be needed to confirm the results.

In conclusion, clinicians can be confident of the specificity of the antigenic bands for the diagnosis of $\mathrm{A}$. cantonensis and G. spinigerum in eosinophilic meningitis.

\section{REFERENCES}

Anantaphruti MT, Nuamtanong S, Dekumyoy P 2005. Diagnostic values of IgG4 in human gnathostomiasis. Trop Med Int Health 10: 1013-1021.

Chun CS, Kazacos KR, Glaser C, Bardo D, Dangoudoubiyam S, Nash R 2009. Global neurologic deficits with baylisascaris encephalitis in a previously healthy teenager. Pediatr Infect Dis J 28: 925-927.

Eamsobhana P, Yoolek A, Punthuprapasa P, Suvouttho S 2001. A dot-blot ELISA comparable to immunoblot for the specific diagnosis of human parastrongyliasis. Asian Pac J Allergy Immunol 19: 267-273.

Intapan PM, Khotsri P, Kanpittaya J, Chotmongkol V, Sawanyawisuth $\mathrm{K}$, Maleewong W 2010. Immunoblot diagnostic test for neurognathostomiasis. Am J Trop Med Hyg 83: 927-929.

Kuberski T 2006. Angiostrongyliasis. In RL Guerrant, DH Walker, PF Weller, Tropical infectious diseases: principles, pathogens and practice, Churchill Livingstone, Philadelphia, p. 1225-1230.

Laemmli UK 1970. Cleavage of structural proteins during the assembly of the head of bacteriophage T4. Nature 227: 680-685.

Laummaunwai P, Sawanyawisuth K, Intapan PM, Chotmongkol V, Wongkham C, Maleewong W 2007. Evaluation of human IgG class and subclass antibodies to a 24-kDa antigenic component of Gnathostoma spinigerum for the serodiagnosis of gnathostomiasis. Parasitol Res 101: 703-708.

Maleewong W, Sombatsawat P, Intapan PM, Wongkham C, Chotmongkol V 2001. Immunoblot evaluation of the specificity of the 29-kDa antigen from young adult female worms Angiostrongylus cantonensis for immunodiagnosis of human angiostrongyliasis. Asian Pac J Allergy Immunol 19: 267-273.

Moreira-Silva SF, Rodrigues MG, Pimenta JL, Gomes CP, Freire LH, Pereira FE 2004. Toxocariasis of the central nervous system: with report of two cases. Rev Soc Bras Med Trop 37: 169-174.

Nopparatana C, Setasuban P, Chaicumpa W, Tapchaisri P 1991. Purification of Gnathostoma spinigerum specific antigen and immunodiagnosis of human gnathostomiasis. Int J Parasitol 21: 677-687.

Page LK, Anchor C, Luy E, Kron S, Larson G, Madsen L, Kellner $\mathrm{K}$, Smyser TJ 2009. Backyard raccoon latrines and risk for Baylisascaris procyonis transmission to humans. Emerg Infect Dis 15: $1530-1531$.

Punyagupta S, Bunnag T, Juttijudata P 1990. Eosinophilic meningitis in Thailand. Clinical and epidemiological characteristics of 162 patients with myeloencephalitis probably caused by Gnathostoma spinigerum. J Neurol Sci 96: 241-256.

Ramirez-Avila L, Slome S, Schuster FL, Gavali S, Schantz PM, Sejvar J, Glaser CA 2009. Eosinophilic meningitis due to Angiostrongylus and Gnathostoma species. Clin Infect Dis 48: 322-327.

Sawanyawisuth K, Sawanyawisuth K 2008. Treatment of angiostrongyliasis. Trans R Soc Trop Med Hyg 102: 990-996.

Solomon T, Danesi M, Bia FJ, Plekc TP 2006. Neurologic disease. In RL Guerrant, DH Walker, PF Weller, Tropical infectious diseases: principles, pathogens and practice, Churchill Livingstone, Philadelphia, p. 1601-1608.

Tapchaisri P, Nopparatana C, Chaicumpa W, Setasuban P 1991. Specific antigen of Gnathostoma spinigerum for immunodiagnosis of human gnathostomiasis. Int J Parasitol 21: 315-319.

Towbin H, Staehelin T, Gordon J 1979. Electrophoretic transfer of proteins from polyacrylamide gels to nitrocellulose sheets: procedure and some applications. Proc Natl Acad Sci USA 76: 4350-4354.

Wang QP, Lai DH, Zhu XQ, Chen XG, Lun ZR 2008. Human angiostrongyliasis. Lancet Infect Dis 8: 621-630.

Wilson ME, Weller PF 2006. Eosinophilia. In RL Guerrant, DH Walker, PF Weller, Tropical infectious diseases: principles, pathogens and practice, Churchill Livingstone, Philadelphia, p. 1478-1495. 